\title{
EXPERIMENTAL INVESTIGATION OF NON-UNIFORM HEATING ON FLOW BOILING INSTABILITIES IN A MICROCHANNELS BASED HEAT SINK
}

\author{
D. Bogojevic ${ }^{1}$, K. Sefiane ${ }^{1}$, A. J. Walton ${ }^{1}$, H. Lin ${ }^{1}$, G. Cummins ${ }^{1}$, D.B.R. Kenning ${ }^{2}$, T.G. Karayiannis ${ }^{2}$ \\ ${ }^{1}$ School of Engineering and Electronics, University of Edinburgh, Mayfield Road, King's Buildings, \\ EH9 3JL Edinburgh, UK \\ ${ }^{2}$ School of Engineering and Design, Brunel University, Uxbridge, Middlesex UB8 3PH, UK \\ Corresponding author: K.Sefiane@ed.ac.uk
}

\begin{abstract}
Two-phase flow boiling in microchannels is one of the most promising cooling technologies able to cope with high heat fluxes generated by the next generation of central processor units (CPU). If flow boiling is to be used as a thermal management method for high heat flux electronics it is necessary to understand the behaviour of a non-uniform heat distribution, which is typically the case observed in a real operating CPU. The work presented is an experimental study of two-phase boiling in a multi-channel silicon heat sink with nonuniform heating, using water as a cooling liquid. Thin nickel film sensors, integrated on the back side of the heat sinks were used in order to gain insight related to temperature fluctuations caused by two-phase flow instabilities under non-uniform heating. The effect of various hotspot locations on the temperature profile and pressure drop has been investigated, with hotspots located in different positions along the heat sink. It was observed that boiling inside microchannels with nonuniform heating led to high temperature non-uniformity in transverse direction.
\end{abstract}

\section{INTRODUCTION}

Two-phase flow boiling in microchannels has been subject of many investigations in recent years as the most promising cooling technology able to cope with high heat fluxes generated by the next generation of central processor units (CPU) [1]. Such cooling technology yields high heat transfer coefficients using low coolant flow rates that require reduced pumping power. However, the main drawbacks of this approach to cooling are backflow and instabilities encountered during boiling in the microchannels. This results in a lower critical heat flux (CHF) than would be obtained with stable flow in microchannels based heat sinks [2]. Whilst the averaged heat flux on CPU can be lower than critical heat flux, local heat fluxes can be very high with damaging consequences [3]. These two-phase flow instabilities during boiling in microchannels under uniform heat flux have been reported by many authors [4-6] and can be avoided by installing small orifices at the inlet of each channel at the cost of an increase in pressure drop [7].

Another big challenge for the microchannel cooling technology is to fully characterise local hotspots and their effects on the system. It is known that CPUs work with nonuniform thermal dissipation that causes localized hotspots resulting in an increase in local CPU junction temperature affecting the reliability and performance of the CPU. This has not been fully investigated and it is essential that this phenomenon is more fully characterised. Eun Seok et al. [8] have experimentally investigated the impact of liquid distribution within channels on the temperature field in a microchannels heat sink with hotspots. The authors compared the performance of two microchannels heat sinks: a regular microchannel heat sink and a cross-linked microchannel heat sink. They found that optimal microchannel heat sink configuration depends on the required flow rate and hotspot position. Jae-Mo et al. [9] carried out simulations using a theoretical model to examine the effect of hotspot location on the pressure drop in two-phase flow region and maximum wall temperature. They found that a hotspot located downstream showed better performance in terms of the pressure drop and maximum wall temperature than one located upstream in the microchannel heat sink. Revellin et al. [10] used numerical simulations to investigate the effects of a number of parameters (mass flux, saturation temperature, microchannel diameter, heated length, size, location and number of hotspots as well as the distance between two consecutive hotspots) on the maximum dissipation rates during flow boiling in a microchannel with non-uniform heating. The authors proposed that, for hotspots situated in the mid-point along the length of the microchannel element, the fluid inlet would be better 
located at the mid-point with an exit at both ends. It is clear that despite numerous attempts, the investigation of the effect of hotspots (magnitude and location) remains a crucial question for the design of microchannels based heat sinks.

This work presents an experimental study of flow boiling in non-uniformly heated silicon heat sink consisting of 40 parallel rectangular microchannels with hydraulic diameters of $194 \mu \mathrm{m}$, using water as a cooling liquid. The experimental work has been conducted with hotspots located at three different positions along the length of the microchannel heat sink (upstream, middle and downstream). Two-phase flow instabilities, previously observed under uniform heating, have also been observed for non-uniform heating. Thin nickel film thermometers integrated on the back side of the silicon chip were used to obtain temperature profile in both the axial and transverse direction. The effect of various hotspot locations on temperature profile and pressure drop has been investigated.

\section{EXPERIMENTAL SETUP AND PROCEDURE}

The test module was a silicon heat sink with 40 parallel rectangular channels, $15 \mathrm{~mm}$ long, $273 \mu \mathrm{m}$ deep, $150 \mu \mathrm{m}$ wide with the spacing between channels being $100 \mu \mathrm{m}$. The microchannels with integrated inlet and outlet manifolds were etched into a silicon wafer using a deep reactive ion etching process. The depth of the inlet/outlet manifold is the same as the depth of the microchannels. A $500 \mu \mathrm{m}$ thick Pyrex glass cover plate was anodically bonded to the silicon wafer to seal and enable visualisation of boiling within channels. The microchannel heat sink, together with the locations of temperature sensors (T1-T5), the inlet/outlet hole and the upstream, middle and downstream hotspot are shown schematically in Fig. 1.

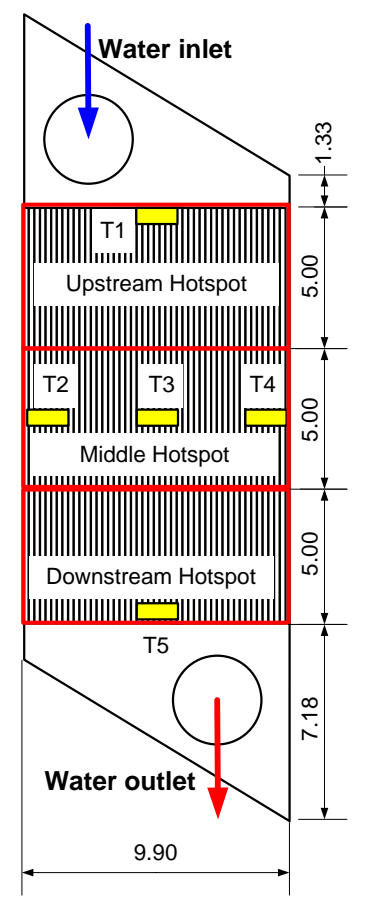

Figure 1. Schematic of the microchannel based heat sink showing the location of the temperature sensors (T1-T5) and position of the upstream, middle and downstream hotspots. Units mm.
On the back side of the device there are five integrated sensors made from a thin nickel film for temperature measurements and an aluminium heater track for heating the microchannels area. The heater was designed to enable either uniform or nonuniform heating, the later being achieved by the independent operation of the upstream, middle or downstream heating elements. In the test rig a single device is placed in a sandwich between top and bottom frames made from a plastic with good thermal insulation properties (Fig. 2). The top frame of the device holder is designed to enable water supply through external stainless steel tubes, connected to the inlet/outlet holes drilled in the Pyrex glass cover plate. The bottom part of the holder is designed to provide the electrical connections required for the heaters and the temperature sensors. Water is supplied into the test module through a flow loop with a variable gear pump. Flow rates are measured by a thermal mass flow meter calibrated in a range of 1 to $50 \mathrm{~g} / \mathrm{min}$ based on water. Inlet water temperature is maintained constant using circulation electrical pre-heater coupled with a PID controller. Any vapour generated in the test module returns to the reservoir where it condenses. The water reservoir-condensing chamber is kept under atmospheric pressure during the experiments.

Pressure, temperature and voltage from the microsensors were acquired and recorded using a 16-bit NI SCXI 1600 data acquisition system from National Instruments and a LabView software interface. Two absolute pressure transducers and two T-type thermocouples, located immediately upstream and downstream of the test module were also used for monitoring the inlet/outlet pressures and temperatures respectively. The pressure transducers used (Omega PXM219 series) have a full scale accuracy of $0.25 \%$ (2.5 bar) and a response time of $2 \mathrm{~ms}$. The standard accuracy of the thermal mass flow meter (Bronkhorst L30 Series) was $\pm 0.5 \mathrm{~g} / \mathrm{min}$. The uncertainties related to thermocouples measurements were $\pm 0.5{ }^{\circ} \mathrm{C}$ for $\mathrm{T}$ type thermocouples.

The integrated sensors were calibrated using a reference $\mathrm{T}$ type thermocouple to characterise the temperature-resistance relationship. The sensors had a typical sensitivity of $3.3 \Omega /{ }^{\circ} \mathrm{C}$ and an accuracy of $\pm 0.5{ }^{\circ} \mathrm{C}$ using the present acquisition system. The thermal time constant associated with the nickel sensors was $1.6 \times 10^{-4} \mathrm{~s}$. Temperatures on the sensors and the inlet/outlet pressures were sampled at rates of 100 and $50 \mathrm{~Hz}$. The test module inlet temperature was maintained within \pm 1 ${ }^{\circ} \mathrm{C}$.

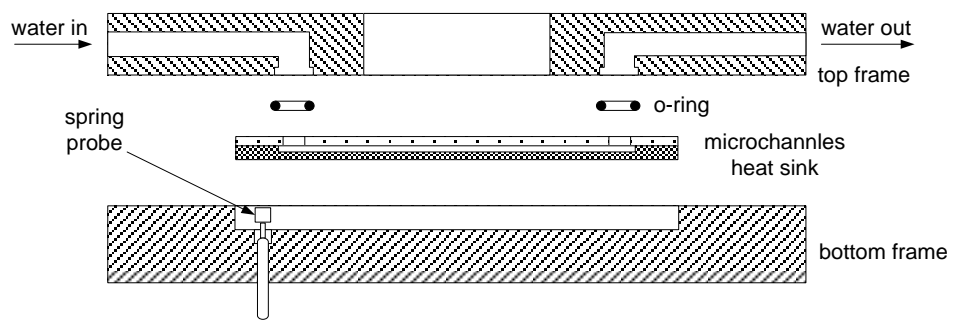

Figure 2. Test module construction 
The heaters on the back side of the device were powered by DC power supply and the power was derived using the applied voltage and the resulting current with a $1 \%$ uncertainty according to the manufacturer specifications. Visualization of boiling within channels was performed using a high speed camera, mounted on a microscope with axial illumination and a $5 \times$ objective.

Prior to carrying out the experiments, deionised water in the reservoir was degassed by vigorous boiling it for approximately one hour. Afterwards, the flow rate and the inlet water temperature were adjusted to the desired values. Experiments were conducted for water mass flow rates of 10 and $17 \mathrm{~g} / \mathrm{min}$ with a water inlet temperature of $71{ }^{\circ} \mathrm{C}$. For each of the mass flow rates one heater element (hotspot) was varied over a range of power while the other two heater elements were powered at a constant power of $10 \mathrm{~W}$ each.

\section{RESULTS AND DISCUSSION}

Two-phase flow instabilities were observed during flow boiling in the microchannels heat sink with non-uniform heating. Fig. 3 shows temporal measurements of the temperature recorded on the five integrated sensors for the cases of: upstream hotspot (a), middle hotspot (b) and downstream hotspot (c), for a mass flow rate of $17 \mathrm{~g} / \mathrm{min}$, inlet water temperature of $71{ }^{\circ} \mathrm{C}$ and two different power magnitudes applied to the hotspot. Two types of the instabilities with appreciable oscillations in pressures and temperatures were observed, similar in frequencies as those observed under uniform heating [11]. First type of instabilities was observed when lower power level was applied to the hotspot. Pressures and temperatures oscillated with higher amplitude and lower frequencies than in the case of second type of instabilities when higher power was applied to the hotspot.

Large amplitude fluctuations in T1 (fig. 3a, 24.8W) indicate intermittent boiling at upstream hotspot. Oscillations of T2 temperature were most of the time below the saturation temperature $\left(\sim 100{ }^{\circ} \mathrm{C}\right)$ while $\mathrm{T} 3$ and $\mathrm{T} 4$ temperatures were always below the saturation temperature, thus bubbles coming from upstream condensed in region of the middle hotspot. Oscillations of T5 temperature with maxima between 102 and $105{ }^{\circ} \mathrm{C}$ indicate more established boiling downstream. In the case of middle hotspot (fig. 3b, 28.6W) temperature T1 was always subcooled indicated a fluctuation in single phase liquid cooling, driven by the flow instabilities originating from middle hotspot boiling. Temperatures T2, T3 and T4 had the same minimum of $100{ }^{\circ} \mathrm{C}$, indicating saturated boiling in middle hotspot region. Temperature $\mathrm{T} 5$ fluctuates between $95{ }^{\circ} \mathrm{C}$ and $105{ }^{\circ} \mathrm{C}$ at somewhat higher frequency then the other sensors probably due to combination of local boiling and flow disturbances driven by middle hotspot boiling. Fig. 3c $(\mathrm{Q}=$ $24.3 \mathrm{~W}$ ) shows dominant subcooled conditions at upstream and middle locations (temperatures T1-T4). Cooling on the first two heaters was a single phase liquid, since there was no superheat to drive evaporative cooling. The large amplitude fluctuations of temperature $\mathrm{T} 5$ are in phase with the fluctuations at T1-T4 but there were some additional smaller amplitude fluctuations. This suggest that the main activity was downstream hotspot boiling with bubble confinement occurring at low frequency and driving the fluctuations observed elsewhere. Fig. 4 shows temporal measurements of inlet/outlet pressures and temperatures T2, T3 and T4 for a power of $26.5 \mathrm{~W}$ applied to middle hotspot and a flow rate of $17 \mathrm{~g} / \mathrm{min}$. The frequency is the same for the inlet/outlet pressure and the temperatures T2, T3 and T4 located in the middle hotspot. All these fluctuations are in phase.

Simultaneously high speed camera imaging showed that oscillations are caused by the flow alternating between liquid, two-phase and vapour. To illustrate these oscillations, fig. 5 shows selected images recorded at a rate of $500 \mathrm{fps}$ for $26.5 \mathrm{~W}$ applied to the middle hotspot, at a mass flow rate of $17 \mathrm{~g} / \mathrm{min}$ and water inlet temperature of $71{ }^{\circ} \mathrm{C}$. The image recorded at $\mathrm{t}=$ $0 \mathrm{~ms}$, shows bubble nucleation inside the microchannels above the middle hotspot. The arrow in the first image shows the direction of the water flow and the circle marks the nucleation site. Initially, the bubble grew remaining at the place of nucleation. At $\mathrm{t}=98 \mathrm{~ms}$ bubble detached from nucleation site and moved downstream. This stage was followed by bubble axial growth causing the bubbles to expand both upstream and downstream coalescing with another bubbles growing at the same nucleation site. After bubbles coalescence, transient annular flow was formed $(\mathrm{t}=138 \mathrm{~ms})$. A thin liquid film evaporation led to temporal "dry out" period in observed channel with nucleation site as shown in the image captured at $t$ $=286 \mathrm{~ms}$. The latter corresponds to maxima in measured temperatures. Vapour is condensed by incoming subcooled liquid and a new cycle starts again with bubble nucleation when the subcooled liquid refills the channel downstream from the nucleation site $(\mathrm{t}=388 \mathrm{~ms})$. This corresponds to minima in measured temperatures and pressures in fig. 4. The average period between two successive refills measured from the film captured using high speed camera is $404 \mathrm{~ms}$. The average time between two successive temperatures and inlet/outlet pressures minima measured from a simultaneously acquired experimental data set (fig 4) is $0.4 \mathrm{~s}$ and it is in good agreement with the time measured from the film.

It was observed that the period between two successive events during alternations of liquid/two-phase/vapour flow and bubbles growth period became shorter when a higher power was applied to the hotspot. This led to a higher oscillation frequency with smaller amplitudes in temperatures, as shown in fig. 3 for the higher power level. In the case of upstream hotspot with a power of $31.4 \mathrm{~W}$ there was a large difference between temperatures measured in transverse direction (T2, T3 and T4, fig. 3a) indicating a non-uniform liquid distribution within the channels. Temperature T4 shows high subcooling conditions inside the channels located above the sensor T4, with fluctuations being completely different from fluctuations in temperatures measured with other sensors. This suggest that there was boiling activity over at least half the width of the channel assembly from T2 to T3 and T5 that diverted single phase liquid flow towards the T4 side of the assembly. The fluctuations of temperature $\mathrm{T} 4$ were in phase with the fluctuations in inlet and outlet pressures with similar frequency of oscillations. This indicates that the fluctuations in T4 were driven by pressure fluctuations. There was a significant difference in temperatures along transverse direction (T2, T3 and T4) in the case of middle hotspot with a power of $32.0 \mathrm{~W}$ applied to the middle heater. However, boiling was observed over total width of the channel assembly from T2 to T4 sensor. The latter is confirmed by temperatures T2, T3 and T4 higher than the saturation temperature. A higher power of $33.7 \mathrm{~W}$ 

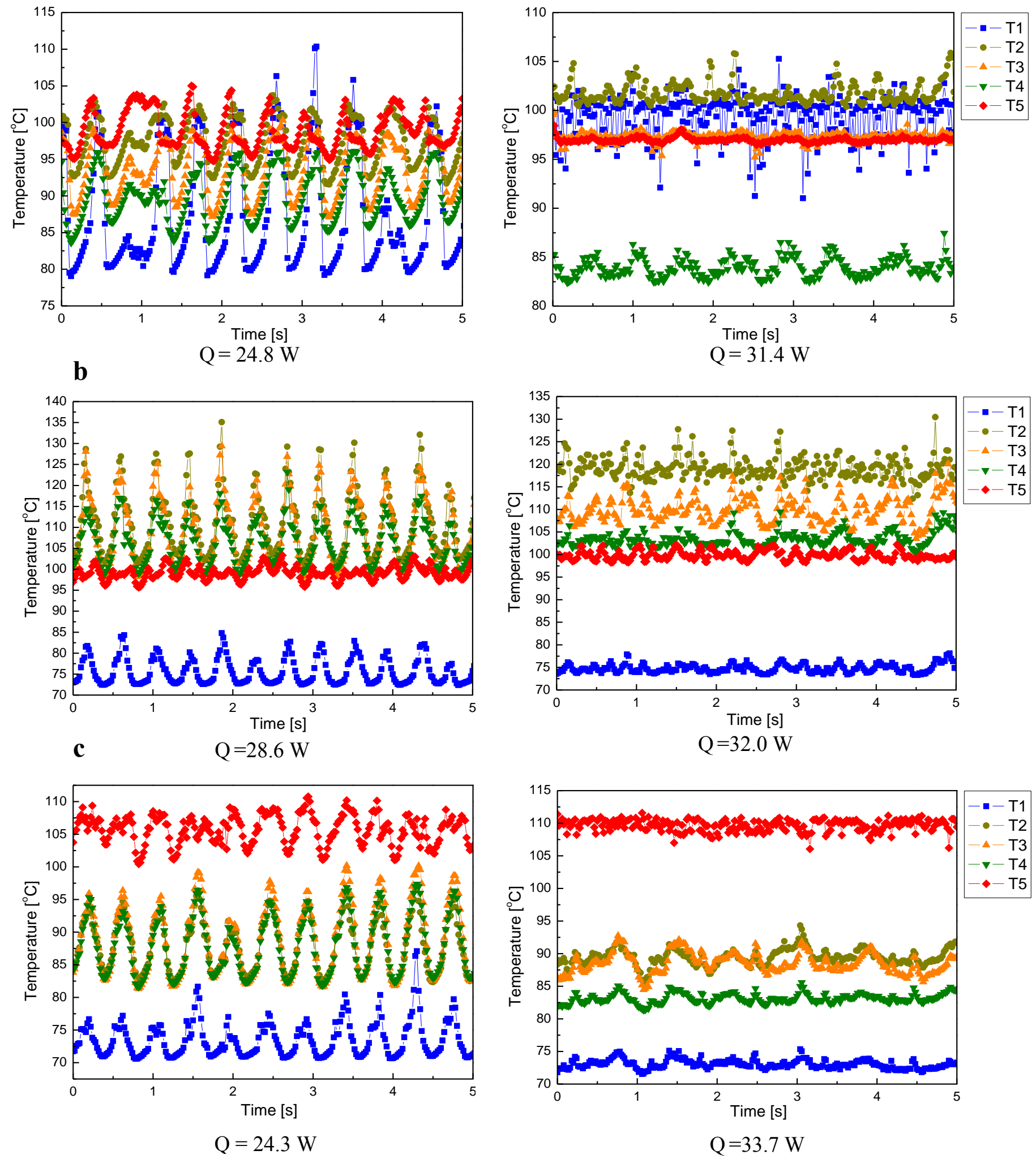

Figure. 3 Temporal measurements of the temperature recorded on the five integrated sensors. (a) upstream hotspot, (b) middle hotspot, (c) downstream hotspot. 
applied on the downstream hotspot settled down the temperature fluctuations observed at lower power as it can be seen in fig. 3c. Boiling was restricted to downstream hotspot as only $\mathrm{T} 5$ sensor recorded temperatures above the saturation temperature. However, all the other temperatures measurements exhibited irregular fluctuations. These fluctuations were driven by downstream hotspot boiling and they were closely correlated in time.

Fig. 6 shows temperature distribution with respect to the power applied to upstream hotspot (a), middle hotspot (b) and downstream hotspot (c), for two water mass flow rates of 10 and $17 \mathrm{~g} / \mathrm{min}$, and water inlet temperature of $71{ }^{\circ} \mathrm{C}$. Each point in the graphs is an average value from one experimental data set. The vertical line (OFI in graphs) shows threshold of twophase flow instabilities when appreciable fluctuations in temperature and inlet/outlet pressure were observed. The vertical bars in the graphs present the magnitudes (minima and

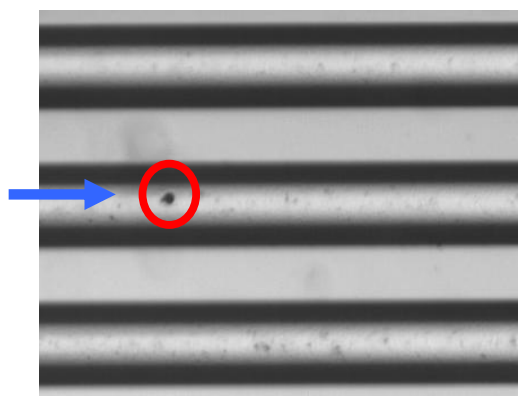

$\mathrm{t}=0 \mathrm{~ms}$

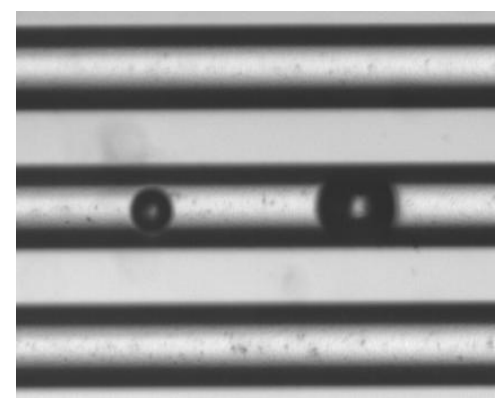

$\mathrm{t}=126 \mathrm{~ms}$

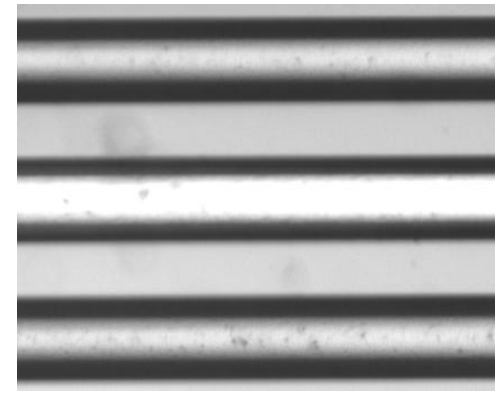

$\mathrm{t}=286 \mathrm{~ms}$

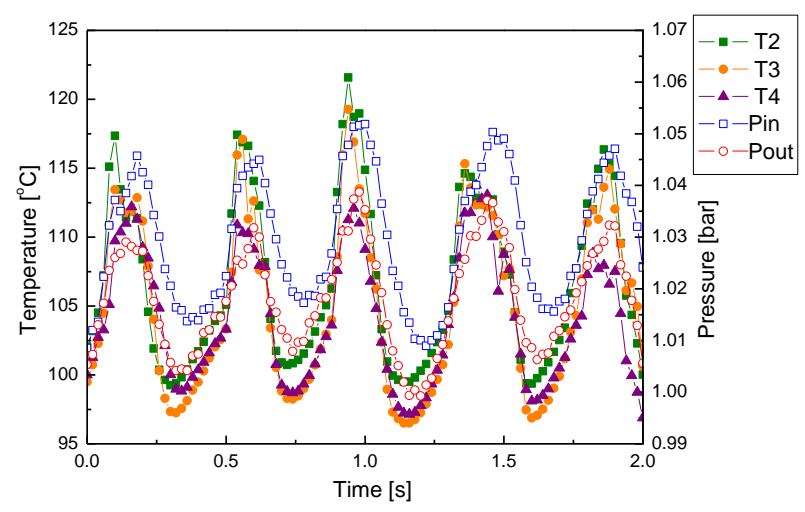

Figure 4. Temporal measurements of temperatures and pressures for a power of $26.5 \mathrm{~W}$ applied to middle hotspot

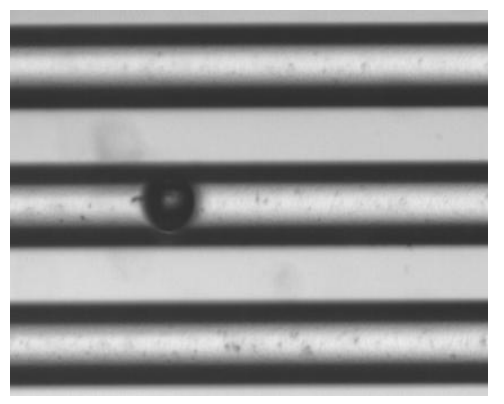

$\mathrm{t}=98 \mathrm{~ms}$

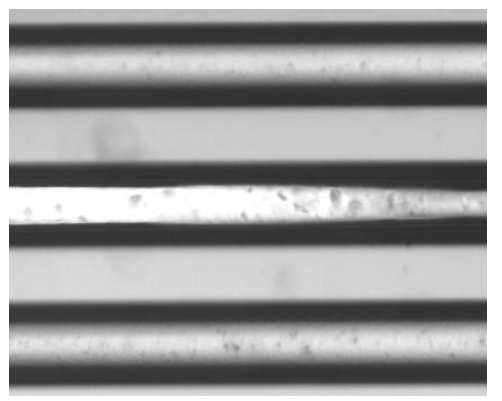

$\mathrm{t}=138 \mathrm{~ms}$

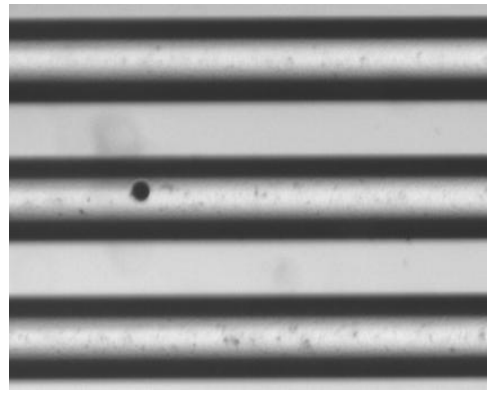

$\mathrm{t}=388 \mathrm{~ms}$

Figure 5. Images recorded at a rate of $500 \mathrm{fps}$ for $24.8 \mathrm{~W}$ power applied to the upstream hotspot. 
maxima values) of temperature on hotspot (T1 for upstream, T3 for middle and T5 for downstream hotspot). The highest temperature amplitudes were recorded by the upstream (T1) and middle (T2, T3 and T4) sensors when located below operating hotspots. However, in the case of downstream hotspot the highest amplitudes of temperature were observed at upstream locations. This was observed for both mass flow rates
(10 and $17 \mathrm{~g} / \mathrm{min}$ ) investigated. The onset of flow instabilities was usually observed at the beginning of boiling inside the microchannels, resulting in a change of slope shown in Fig. 6 . The changes in slope are more pronounced for the higher mass flow rate of $17 \mathrm{~g} / \mathrm{min}$. For upstream hotspot, boiling inside microchannels caused increased temperature T1 measured at the inlet of the microchannels. On the outlet side of the channel

a
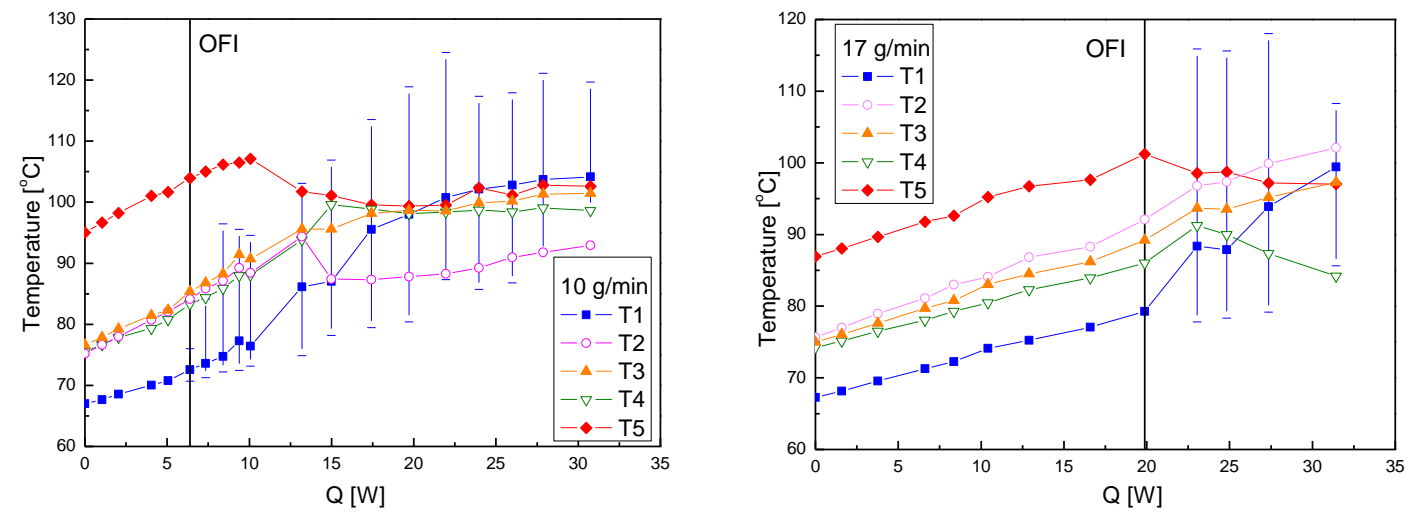

b
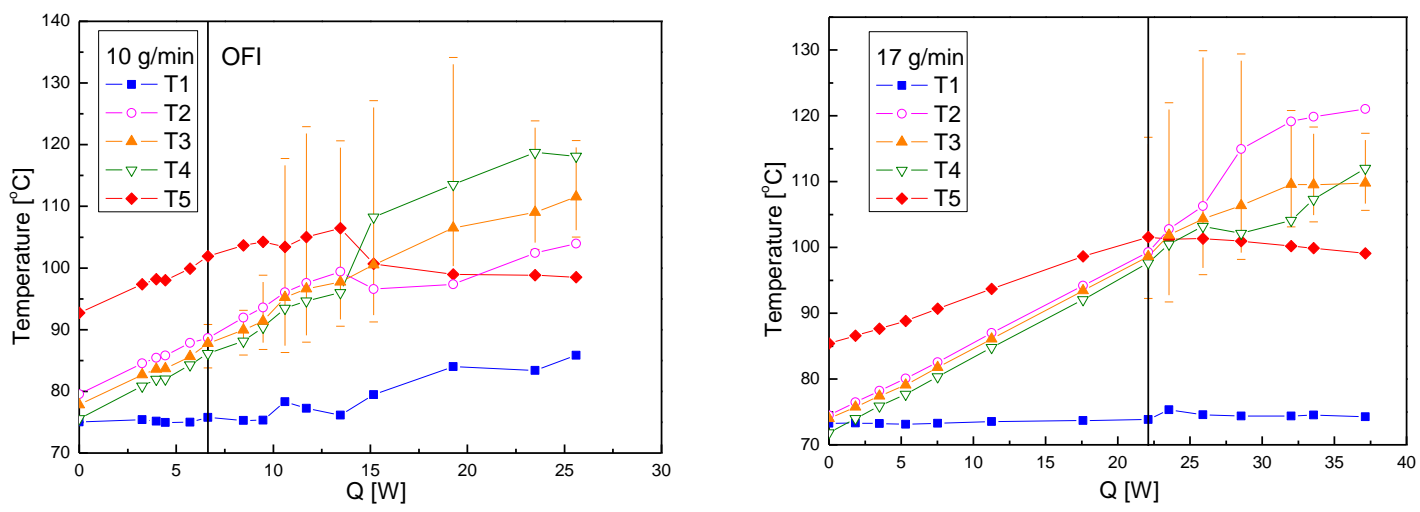

c
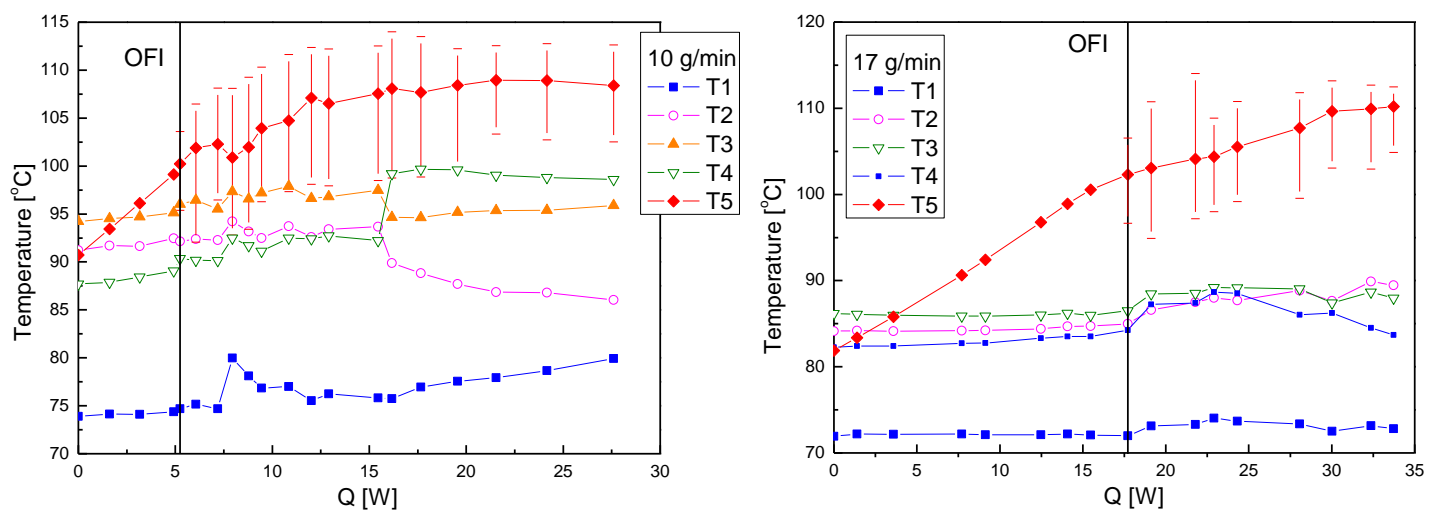

Figure 6. Temperature distribution with respect to the power applied. (a) upstream hotspot, (b) middle hotspot, (c) downstream hotspot. Vertical bars present the magnitudes of temperature (a) T1, (b) T3, (c) T5. 
temperature T5 decreased. A similar effect was observed in the case of a middle hotspot when an increase in the power was applied to the hotspot, during the boiling inside the heat sink, resulted in a decrease in temperature T5. Once boiling occurred inside the microchannels with hotspot located downstream, the slope related to the temperature T5 in Fig. 6(c) decreases. After the onset of flow instabilities, further increase of the power applied on downstream hotspot did not affect significantly mean values of temperatures at upstream locations (T1, T2, T3 and T4). The prevailing single phase flow was observed in upstream location and good lateral flow distribution indicated by temperatures $\mathrm{T} 2$ and $\mathrm{T} 4$ being very similar. However, high power applied to downstream hotspot, breaks up temperature uniformity in the transverse direction as the boiling propagates towards the inlet of the heat sink.

Fig. 7 depicts the temperature distribution in axial direction (a) and transverse direction (b) for different locations of the hotspot, two magnitudes of power applied to the hotspot and a mass flow rate of $17 \mathrm{~g} / \mathrm{min}$. The axial temperature distribution is presented with averaged temperatures measured by sensors T1, T3 and T5 located at $0.367,7.500$ and $14.632 \mathrm{~mm}$ respectively from the channels inlet. The transverse temperature distribution is presented with averaged temperatures measured by sensors $\mathrm{T} 2, \mathrm{~T} 3$ and $\mathrm{T} 4$ located at $1.005,5.000$ and $8.995 \mathrm{~mm}$ respectively from the edge of the channels assembly. Fig. 7a shows that a hotspot located upstream yielded a better axial temperature distribution. The smallest temperature difference along axial direction occurred with upstream located hotspot. For $17 \mathrm{~g} / \mathrm{min}$ flow rate and the hotspot located downstream the difference between temperatures along the transverse direction was smaller than the other two hotspot locations (fig $7 \mathrm{~b}$ ). This implies that a hotspot located downstream resulted in better temperature uniformity in the transverse direction than upstream and middle hotspot locations.

The temperature non-uniformity in transverse direction increases with the increasing power applied to hotspot. Again, temperature non-uniformity was more pronounced for the middle and upstream hotspots than the downstream hotspot. The temperature distribution in transverse direction strongly depends on mass flow distribution within the microchannels. It was observed that boiling was not uniformly established in transverse directions. The pressure drop due to boiling established on one side of the channels assembly diverted single phase liquid flow towards another side of the microchannels heat sink. This caused difference between the average values of the temperatures in transverse direction and inconsistency in their oscillation amplitude and frequency.

Fig. 8 shows the pressure drop with respect to the power applied to upstream, middle and downstream hotspots for mass flow rates of 10 and $17 \mathrm{~g} / \mathrm{min}$. Each point in the graphs is an average value from one experimental data set. The applied power was varied over a given range, while the other two heater elements were both maintained at a constant power of 10 W. It was found for both mass flow rates that a middle located hotspot resulted in the lowest pressure drop once boiling occurred inside the heat sink. In contrast, the highest pressure drop was recorded for upstream located hotspot when boiling took place in the heat sink. It is suggested that this higher pressure drop is due to the interaction between the vapour generated at the upstream region and the compressible volume of the inlet manifold. It is also worth noting that boiling first occurred at the outlet manifold before starting inside the microchannels and increasing the pressure drop. Pressure drop analysis showed that the magnitude of pressure drop oscillations (difference between the maximum and minimum value from one experimental data set) was higher for upstream and middle located hotspots than for downstream located hotspot. This was observed for both mass flow rates (10 and 17 $\mathrm{g} / \mathrm{min}$ ) investigated. A long subcooled inlet region, in the case of downstream hotspot, suppressed flow reversals originating at the downstream end of the channels, by partially condensing reversing bubbles. This resulted in smaller magnitudes of the pressure drop oscillations.

a
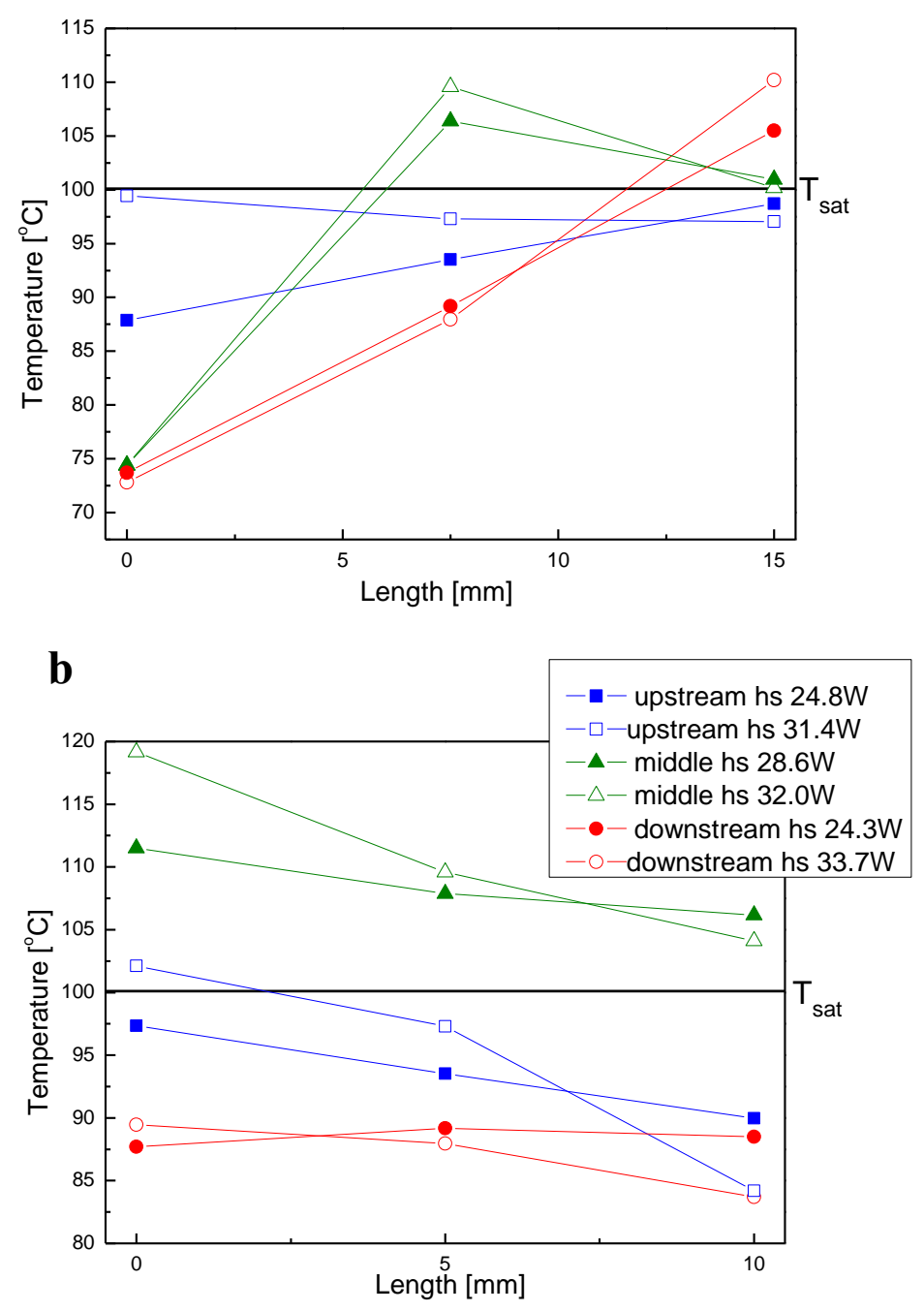

Figure 7. Temperature distribution in axial direction (a) and transverse direction (b) for two power applied to upstream, middle and downstream hotspots. 

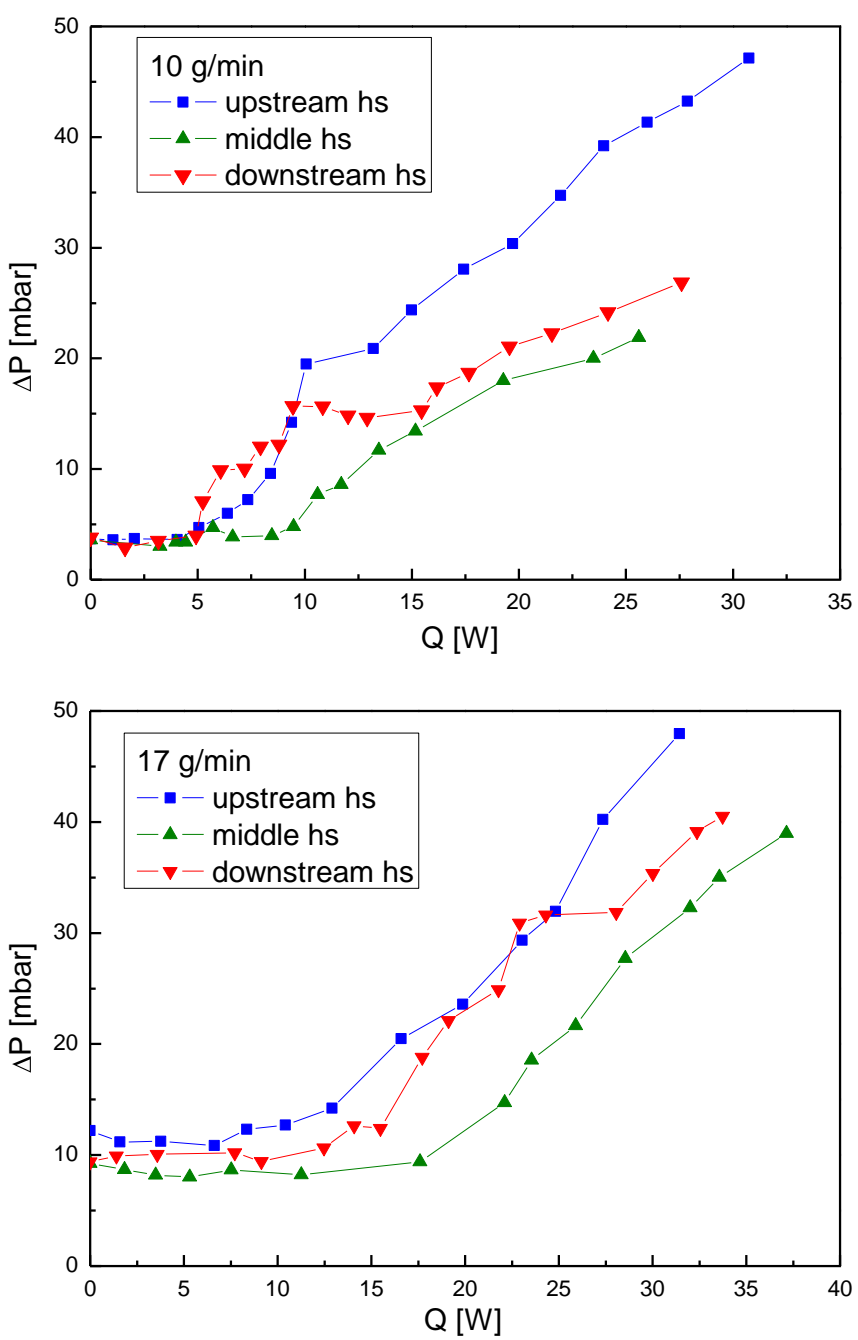

Figure 8. Pressure drop with respect to the applied power to upstream, middle and downstream hotspot for mass flow rates of 10 and $17 \mathrm{~g} / \mathrm{min}$.

\section{CONCLUSION}

A series of experiments have been carried out to investigate the performance of a silicon microchannel based heat sink under non-uniform heating conditions. Two mass flow rates of 10 and $17 \mathrm{~g} / \mathrm{min}$ were used and the effect of nonuniform heating on temperature distribution and pressure drop has been assessed, with hotspots located upstream, middle and downstream along the heat sink. Two-phase flow instabilities have been observed, with a characteristic oscillation in temperature and pressure. The highest amplitudes of temperature were recorded by the sensors located below the upstream and middle hotspots, while in case of downstream located hotspot, the highest amplitudes of temperature were observed at upstream locations. It was observed that boiling inside microchannels with non-uniform heating led to high temperature non-uniformity in transverse direction caused by diversion of single phase liquid flow towards one side of the heat sink assembly. For a higher mass flow rate of $17 \mathrm{~g} / \mathrm{min}$, a downstream hotspot resulted in better temperature uniformity than upstream and middle hotspots. On the other hand, a hotspot located upstream provided better axial temperature distribution. The highest pressure drop was found for the case of upstream located hotspot when boiling takes place in the heat sink. This is due to the interaction between the vapour generated in the upstream region and the compressible volume of the inlet manifold. It has also been shown that the magnitude of the pressure drop oscillation is higher for upstream and middle hotspots than is the case for downstream located hotspot.

\section{NOMENCLATURE}

Q power, $\mathrm{W}$

$\mathrm{T}$ temperature, ${ }^{\circ} \mathrm{C}$

$\mathrm{t}$ time, $\mathrm{s}$

\section{Greek}

$\Delta \mathrm{P}$ pressure drop, mbar

\section{ACKNOWLEDGMENTS}

This research was supported by the UK Engineering and Physical Sciences Research Council through grant $\mathrm{EP} / \mathrm{D} 500109 / 1$. The authors in the Institute of Integrated Systems would also like to acknowledge support from the Edinburgh Research Partnership in Engineering and Mathematics.

\section{REFERENCES}

1. Lin, S., Sefiane, K., and Christy, J.R.E., Prospects of confined flow boiling in thermal management of microsystems, Applied Thermal Engineering, 22(7), pp. 825-837, 2002.

2. Bergles, A.E., and Kandlikar, S.G., On the Nature of Critical Heat Flux in Microchannels, Journal of Heat Transfer, 127(1), pp. 101-107, 2005.

3. Schmidt, R., Cooling Electronics in the Next Decade, Marlborough, MA,2000.

4. Qu, W.,and Mudawar, I., Measurement and prediction of pressure drop in two-phase micro-channel heat sinks, International Journal of Heat and Mass Transfer, 46(15), pp. 2737-2753, 2003.

5. Hetsroni, G., Mosyak, A., Pogrebnyak, E., and Segal, Z., Explosive boiling of water in parallel microchannels, International Journal of Multiphase Flow, 31(4), pp. 371-392, 2005.

6. Hetsroni, G., Mosyak, A., Pogrebnyak, E., and Segal, Z., Periodic boiling in parallel micro-channels at low vapor quality, International Journal of Multiphase Flow, 32(10-11), pp. 1141-1159, 2006.

7. Kandlikar, S.G., Kuan, W.K., Willistein, D.A., and Borrelli, J., Stabilization of Flow Boiling in Microchannels Using Pressure Drop Elements and Fabricated Nucleation Sites, Journal of Heat Transfer, 128(4), pp. 389-396, 2006.

8. Eun Seok, C., Jae-Mo, K., Linan, J., Prasher, R.S., Min Soo, K., Santiago, J.G., Kenny, T.W., and 
Goodson, K.E., Experimental study on two-phase heat transfer in microchannel heat sinks with hotspots,Semiconductor Thermal Measurement and Management Symposium, 2003. Ninteenth Annual IEEE,2003.

9. Jae-Mo, K., Linan, J., Bari, A., Zhang, L., Wang, E., Kenny, T.W., Santiago, J.G., and Goodson, K.E., Convective boiling in microchannel heat sinks with spatially-varying heat generation, Thermal and Thermomechanical Phenomena in Electronic Systems, 2002. ITHERM 2002. The Eighth Intersociety Conference on, 2002.

10. Revellin, R., Quiben, J.M., Bonjour, J., and Thome, J.R., Effect of Local Hot Spots on the Maximum Dissipation Rates During Flow Boiling in a Microchannel, Components and Packaging Technologies, IEEE Transactions on, 31(2), pp. 407, 2008.

11. Bogojevic, D., Sefiane, K, Walton, A.J., Lin, H., Cummins, G., Two-phase flow instabilities in microchannels", ECI International Conference on Heat Transfer and Fluid Flow in Microscale, ECI International Conference on Heat Transfer and Fluid Flow in Microscale, Whistler, Canada, 21-26

September, 2008. 